\title{
The Revised Sonographic NASCET Index: A New Hemodynamic Parameter for the Assessment of Internal Carotid Artery Stenosis
}

\author{
Revidierter sonografischer NASCET-Index: Ein neuer \\ hämodynamischer Parameter zur Graduierung \\ von A. carotis interna Stenosen
}

Authors

Affiliation
G. Hathout, N. Nayak, A. Abdulla, J. Huang

Radiology, UCLA, Los Angeles, United States

\author{
Key words \\ - ultrasound spectral Doppler \\ - ultrasound Doppler \\ - angiography \\ - vascular \\ - carotid arteries
}

received $\quad 18.5 .2014$

accepted 22.7.2014

Bibliography

Dol http://dx.doi.org/

10.1055/s-0034-1385070

Published online: September 9 , 2014

Ultraschall in Med 2015; 36: 362-368 ๑ Georg Thieme Verlag KG Stuttgart · New York . ISSN 0172-4614

\section{Correspondence}

Dr. Gasser Hathout

Radiology, UCLA

10833 Le Conte Ave

90095 Los Angeles

United States

Tel.: 3 10/2683203

ghathout@ucla.edu

\section{Abstract \\ $\nabla$}

Purpose: A previously described Doppler parameter, the sonographic NASCET index (SNI), was derived to be more directly analogous to the North American Symptomatic Carotid Endarterectomy Trial (NASCET) methodology for assessing carotid artery stenosis. However, this index does not account for complex changes affecting the Doppler waveform. We propose a revised SNI (rSNI) in an effort to improve predicting carotid stenosis.

Materials and Methods: 25 carotid bifurcations with stenoses ranging from $40-92 \%$ were analyzed. For each vessel, the rSNI and original SNI were calculated. The peak systolic velocity (PSV), rSNI, and original SNI were correlated with angiography using linear regression analysis and relative accuracies were compared at two thresholds. Results: A correlation between rSNI and angiography was found to be significantly better than that between PSV or internal carotid artery-common carotid artery (ICA-CCA) peak velocity ratio and angiography ( $r^{2}=0.47$ vs. $0.22 ; r^{2}=0.47$ vs. 0.16$)$. The accuracy of PSV in predicting high-grade stenosis was $68 \%$ and $72 \%$, compared with $80 \%$ and $88 \%$ for rSNI, at each of two thresholds. The original SNI better correlated with angiography compared to the rSNI ( $r^{2}=0.55$ vs. 0.47 ), but with slightly lower accuracy in predicting high-grade stenosis (76\% vs. $80 \%$ ).

Conclusion: The revised SNI correlates more closely with angiographic stenosis than either the PSV or the ICA-CCA ratio, and is more accurate in predicting high-grade stenosis. However, it is overall comparable to the original SNI, suggesting that the previously unaccounted for effects over the remainder of the cardiac cycle do not significantly improve the ability to sonographically predict significant stenosis.

\section{Zusammenfassung \\ $\nabla$}

Ziel: Der in der Literatur beschriebene DopplerParameter „sonografischer NASCET-Index (SNI)“ wurde zur besseren Vergleichbarkeit der Graduierung von Karotisstenosen analog der NASCET Studien Methodologie entwickelt. Allerdings berücksichtigt dieser Index keine komplexen Änderungen des Doppler Spektrums. Wir evaluierten einen revidierten SNI (rSNI), der den Grad einer Karotisstenose besser vorhersagen soll.

Material und Methoden: 25 Karotisbifurkationen mit Stenosen zwischen 40 und $92 \%$ wurden analysiert. Für jedes Gefäß wurden der rSNI und der SNI berechnet. Die systolische Maximalgeschwindigkeit (PSV), der rSNI und der SNI wurden mit der Angiografie anhand linearer Regressionsanalysen korreliert und die relative Genauigkeit für zwei Grenzwerte verglichen.

Ergebnisse: Die Korrelation zwischen dem rSNI und der Angiografie war signifikant besser als die zwischen der PSV oder der A. carotis interna A. carotis communis (ICA-CCA) PSV Ratio und der Angiografie ( $r^{2}=0,47$ vs. 0,$22 ; r^{2}=0,47$ vs. 0,16 ). Die Genauigkeit der PSV zur Prädiktion einer hochgradigen Stenose lag bei $68 \%$ und $72 \%$, verglichen mit $80 \%$ und $88 \%$ für den rSNI an den beiden Grenzwerten. Der originale SNI korrelierte besser mit der Angiografie im Vergleich zum rSNI $\left(r^{2}=0,55\right.$ vs. 0,47$)$, aber hatte eine etwas geringere Genauigkeit zur Vorhersage hochgradiger Stenosen $(76 \%$ vs. $80 \%)$.

Schlussfolgerung: Der revidierte SNI korreliert besser mit der angiografisch gemessenen Stenose als die PSV oder die ICA-CCA Ratio und ist akkurater in der Prädiktion hochgradiger Stenosen. Allerdings ist er insgesamt vergleichbar mit dem originalen SNI, was dafür spricht, dass die zuvor nicht berücksichtigten Effekte des restlichen Herzzyklus' keinen signifikanten Einfluss auf die sonografische Vorhersagbarkeit signifikanter Stenosen haben. 


\section{Introduction}

\section{$\nabla$}

Vascular ultrasound remains an inexpensive and noninvasive modality to evaluate atherosclerotic disease of the extracranial carotid arteries, with accuracy rates for grading carotid stenosis often quoted to exceed $90 \%$ [ $1-11]$. Sonography remains the most widely used initial modality for preoperative evaluation [12, 13], and in patients with high-grade stenoses, provides a cost-effective method of stenosis detection and triage to therapy [14].

Conventionally, the degree of carotid stenosis is indirectly quantified through the use of Doppler parameters that incorporate flow velocity measured at a single point along the proximal internal carotid artery (ICA), such as peak systolic velocity (PSV), or the ICA/CCA peak velocity ratio (VICA/VCCA ratio). Exclusion of high-grade stenosis can be achieved with a high degree of sensitivity [15]. However, both measures have proven to demonstrate significant variability, potentially altering recommendations in a significant subset of patients $[16,17]$. In fact, a recent comprehensive review of the role of ultrasound in grading carotid stenosis concluded that velocity measurements alone in a stenosis (either PSV or VICA/VCCA ratio) are not able to differentiate moderate from severe stenosis ( $>=70 \%$ NASCET) with sufficient clinical reliability [18]. Additionally, the North American Symptomatic Carotid Endarterectomy Trial (NASCET) methodology of carotid stenosis quantification, in which the luminal diameter of diseased ICA is compared to the non-diseased, more distal ICA lumen, is not reflected by either measurement [19].

Previously, we developed a new Doppler parameter, the sonographic-NASCET index (SNI), which measures carotid stenosis in a fashion more analogous to the NASCET methodology, applying the principle of mass balance to peak systolic velocities in the proximal stenotic ICA and the more normal distal ICA [20]. The SNI was shown to have better correlation with the degree of angiographic stenosis than PSV. However, like other Doppler criteria, the SNI uses only single time-point velocity measurements at the peak of the cardiac cycle. Thus, complex physiologic changes affecting the Doppler waveform as a whole, such as increased diastolic flow in the setting of more narrow occlusions, were not taken into account.

We have devised an updated SNI (rSNI), revised to integrate the Doppler waveform within the vessel at both the stenotic proximal ICA and the distal normal ICA over the entire cardiac cycle, and to calculate a NASCET-style measurement of carotid stenosis. Using this updated parameter, we again compare the diagnostic accuracy of the rSNI with PSV.

\section{Methods}

$\nabla$

\section{Material}

We restricted our study to patients with direct catheter angiographic correlation, once again to reflect the methodology used in the original NASCET study. This necessitated a retrospective study using our old angiography database.

A review of all carotid angiographic studies reported at our institution between October 1992 and April 1998 was performed, using the same data set as was utilized for the original SNI computation. Only this older data set is used because after that time, direct catheter angiography was no longer routinely performed for the preoperative evaluation of carotid stenosis. Vessels that were evaluated with both sonography and conventional arteriography were identified, with initial inclusion criteria of angiogra- phically proven stenosis in the range of $40-95 \%$, as well as Doppler measured proximal and distal ICA PSV values. The lower bound was chosen to exclude insignificant degrees of luminal narrowing, while the upper bound was chosen to exclude occlusions and near occlusions with partial luminal collapse, as such vessels do not submit to accurate NASCET-style measurements and may have paradoxically low PSV values [19]. From this subgroup, 25 ICAs with stenoses ranging between $40 \%$ and $92 \%$ as determined with arteriography by using the NASCET methodology were identified (25 ICAs in 22 patients). This represented the subset of vessels where both proximal and distal ICA velocity measurements and Doppler waveforms were available on our institution's picture archiving and communication system (PACS) system. Vessels wherein the reported PSV corresponded to the distal-most velocity observed within the ipsilateral ICA were excluded. Also, heavily calcified plaques where the vessel lumen could not be visualized secondary to shadowing were excluded. It is noted that all data analysis was done after the patient data set was selected and the threshold values were done on the complete data set. In other words, there was no bias in selecting patients to manipulate the threshold values or to influence sensitivity and specificity.

\section{Angiography}

Digital subtraction angiography was performed through a femoral artery approach, with selective injections in the CCAs. At least two orthogonal views of each carotid bifurcation were obtained. In each case, the digital subtraction angiograms were reviewed in a blinded fashion by two experienced neuroradiologists (G. M. H., S.M.E.), and the final results were determined by consensus by averaging the two independent measurements for each vessel. Angiographic percentage stenosis determination was made in accordance with published NASCET guidelines [21].

\section{Sonography}

Carotid sonography was performed by experienced technologists at our institution, and the sonograms were interpreted by an experienced sonologist. Five- or 7.5-MHz linear-array transducers were used, as dictated by patient body habitus. All images were obtained in accordance with an established laboratory protocol. All patients underwent grayscale as well as color and spectral Doppler imaging. Angle adjustment was based on flow direction as depicted by color Doppler. Angle-adjusted spectral Doppler samples were obtained from predetermined sites within each CCA and ipsilateral ICA, including

proximal, middle, and distal sites along the course of each vessel. The highest angle-adjusted velocities observed within each of the proximal, middle, and distal segments of the ICA were routinely recorded by the technologist, and the highest of these recorded velocities was routinely reported as the PSV by the interpreting radiologist. Doppler parameters routinely evaluated and reported for each carotid bifurcation included PSV, EDV, and VICA/ VCCA ratio.

Using GraphClick (Version 3.0.2., Arizona Software, 2010) software, numerical integration was performed on each Doppler velocity-time curve to obtain the area underneath the curve over one cardiac cycle ( $\bullet$ Fig. 1 ), designated as $\int \mathrm{V}(\mathrm{t}) \mathrm{dt}$. When multiplied by the cross-sectional area of the vessel, the expression $\int($ Area $) \mathrm{V}(\mathrm{t}) \mathrm{dt}$ represents the bulk flow over one cardiac cycle in units of volume. 


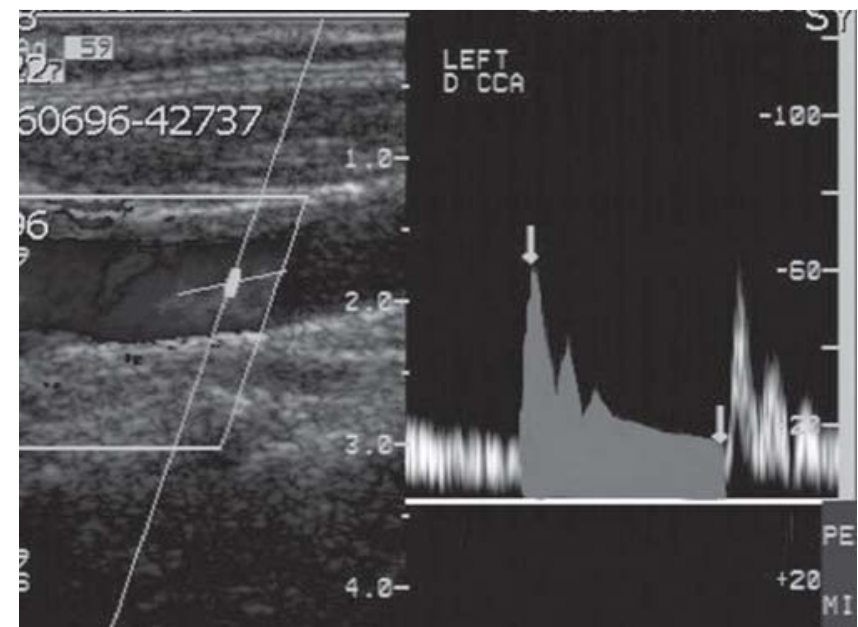

Fig. 1 Graphic representation of the numerical integration performed for each Doppler velocity-time curve to obtain the area underneath the curve over one cardiac cycle.

Abb. 1 Grafische Darstellung der numerischen Integration für jede Doppler-Spektral-Kurve zur Errechnung der Fläche-unter- der-Kurve für einen Herzzyklus.

\section{Definition and Derivation of the Updated SNI}

According to the principle of mass balance, the net flux at two different points along a single, nonbranching vessel must remain equal. With regard to the ICA, the flux proximally at point $p$ (the point of maximal stenosis in the ICA) must equal the flux distally at point $d$ (a more distal point along the normal ICA lumen).

To state this mathematically:

ICA Flux $_{\mathrm{p}}=$ ICA Flux $_{\mathrm{d}}$

Since flux is equal to the flow of blood passing through a defined cross-sectional area per unit time, the ICA flux is equal to the product of the luminal cross-sectional area and flow velocity. Therefore, at the time of peak systolic velocity, we may therefore substitute:

$\left(\right.$ Area $\left._{\mathrm{p}}\right)\left(\right.$ PSV $\left._{\mathrm{p}}\right)=\left(\right.$ Area $\left._{\mathrm{d}}\right)\left(\mathrm{PSV}_{\mathrm{d}}\right)$

This is the basis for the calculation of the original SNI.

We can further infer that true bulk volume within a vessel throughout the cardiac cycle must also remain equal at these two points. The volume can be calculated by the integral of the area under the pulse waveform, which is a blood flow velocity versus time curve, which we will designate $\mathrm{V}(\mathrm{t})$ :

$\int\left(\right.$ Area $\left._{\mathrm{p}}\right) \mathrm{V}_{\mathrm{p}}(\mathrm{t}) \mathrm{dt}=\int\left(\right.$ Area $\left._{\mathrm{d}}\right) \mathrm{V}_{\mathrm{d}}(\mathrm{t}) \mathrm{dt}$

Assuming that the cross-sectional area of the ICA approximates the area of a circle, we may also substitute:

$\pi r_{p}^{2} \int V_{p}(t) d t=\pi r_{p}^{2} \int V_{d}(t) d t$

Rearranging algebraically, we derive:

$\frac{r_{p}}{r_{d}}=\sqrt{\frac{\int v_{d}(t) d t}{\int v_{p}(t) d t}}$

Additionally, the NASCET guidelines for the angiographic measurement of ICA stenosis measure the luminal diameter, $D$, at a point proximal to the maximal stenosis $(p)$ and distally at a point where the ICA lumen becomes normal $(d)$; the resultant percentage stenosis is expressed as:

$\left(1-D_{p} / D_{d}\right) \times 100$

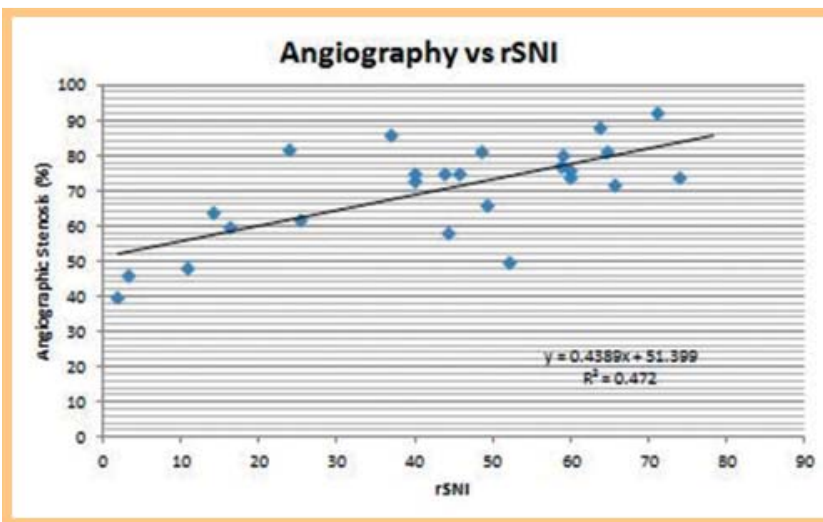

Fig. 2 Linear regression analysis of measured carotid artery angiographic stenosis against the revised SNI (rSNI).

Abb.2 Lineare Regressionsanalyse der angiografisch gemessenen A. carotis Stenose im Vergleich zur revidierten SNI (rSNI).

Recognizing that cross-sectional diameter is equal to twice the radius:

$\mathrm{D}_{\mathrm{p}} / \mathrm{D}_{\mathrm{d}}=2 \mathrm{r}_{\mathrm{p}} / 2 \mathrm{r}_{\mathrm{d}}=\mathrm{r}_{\mathrm{p}} / \mathrm{r}_{\mathrm{d}}$.

Therefore, by substitution,

$\left(1-\mathrm{D}_{\mathrm{p}} / \mathrm{D}_{\mathrm{d}}\right) \times 100=\left(1-\mathrm{r}_{\mathrm{p}} / \mathrm{r}_{\mathrm{d}}\right) \times 100=\left[1-\sqrt{\frac{\int \mathrm{V}_{\mathrm{d}}(\mathrm{t}) \mathrm{dt}}{\int \mathrm{V}_{\mathrm{p}}(\mathrm{t}) \mathrm{dt}}}\right] \times 100$

Thus, we have revised the original SNI in a way that accounts for the bulk volume of blood flow throughout the cardiac cycle, but still mirrors the NASCET methodology for the angiographic determination of ICA stenosis.

For each carotid bifurcation included in our study, values for the rSNI were obtained by using the following equation:

$\mathrm{rSNI}=\left[1-\sqrt{\frac{\int \mathrm{V}_{\mathrm{d}}(\mathrm{t}) \mathrm{dt}}{\int \mathrm{V}_{\mathrm{p}}(\mathrm{t}) \mathrm{dt}}}\right] \times 100$

In this equation, the waveform image corresponding to the originally reported peak ICA PSV was used to calculate the proximal integral; the ipsilateral, distal-most ICA waveform recorded (distal to the region of stenosis) was used to calculate the distal integral.

\section{Regression Model}

We used the standard model of linear regression, assuming that there is a dependent variable, $Y$, which in this case is the measured digital subtraction angiographic stenosis, and an independent variable, $X$, which in this case is the measured Doppler parameter from which $Y$ is to be predicted. Output data and figures for this linear regression analysis were generated using the Excel software package (Microsoft Corporation, Redmond, WA). Regression lines for the PSV, rSNI and original SNI values were plotted against the measured angiographic stenosis values, and the values that corresponded to $70 \%$ angiographic stenosis for PSV and each SNI were determined from these plots. The accuracy of rSNI in predicting $70 \%$ or greater angiographic stenosis was compared with that of PSV using these threshold values.

A second set of threshold values was also obtained using a PSV value of $230 \mathrm{~cm} / \mathrm{s}$, which is the value in clinical use at our institution to identify significant carotid stenosis. Using the linear regression plots, the angiographic stenosis value corresponding to 


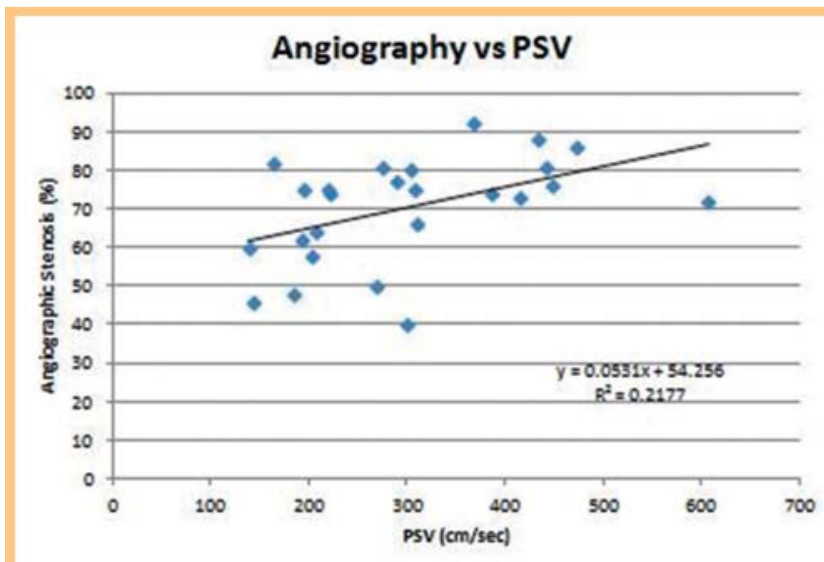

Fig. 3 Linear regression analysis of measured carotid artery angiographic stenosis against the peak systolic velocity (PSV).

Abb.3 Lineare Regressionsanalyse der angiografisch gemessenen A. carotis Stenose im Vergleich zur systolischen Maximalgeschwindigkeit (PSV).

a PSV of $230 \mathrm{~cm} / \mathrm{s}$ on $\bullet$ Fig. 2 was then used to "read off" the corresponding rSNI value from $\bullet$ Fig. 3. Sensitivity, specificity, and accuracy tables for PSV and rSNI at these two different Doppler thresholds were then calculated. Both sets of threshold values were chosen prospectively after the linear regression analysis, but before any calculation of sensitivity, specificity, or accuracy, and thus, were not chosen retrospectively to improve the performance of the rSNI. No other threshold values were evaluated.

\section{Results}

\section{$\checkmark$}

A total of 25 carotid bifurcations were included in the study, with NASCET-style digital subtraction angiographic measurements of linear percentage stenosis ranging from $40 \%$ to $92 \%$. Sonographic PSV measurements ranged from 143 to $607 \mathrm{~cm} / \mathrm{s}$. Distal ICA velocities ranged from 38 to $204 \mathrm{~cm} / \mathrm{s}$. Revised SNI (rSNI) values that were calculated using the described methodology ranged from 1.9 to 73.8 (unit-less parameter). Original SNI values that were calculated using the described methodology ranged from 3.2 to 72.4 (unit-less parameter).

\section{Statistical Analysis}

Linear regression analysis again revealed a better correlation between the rSNI and the measured NASCET linear percentage angiographic stenosis $\left(r^{2}=0.47\right)$ as compared to PSV and measured NASCET linear percentage angiographic stenosis $\left(r^{2}=0.22\right)$. Using the data in $\odot$ Fig. 2 and the associated linear regression equation of angiographic stenosis versus PSV, the value of PSV that corresponded to a NASCET linear percentage angiographic stenosis of $70 \%$ was determined to be $296.5 \mathrm{~cm} / \mathrm{s}$. Similarly, using the data in $\bullet$ Fig. 3 and the associated linear regression equation of angiographic stenosis versus rSNI, the rSNI value that corresponded to a NASCET linear percentage angiographic stenosis of $70 \%$ was determined to be 42.4 . These parameters formed one set of threshold values for comparison of PSV and rSNI. The relevant data is presented in 0 Table 1.

Of the 25 carotid arteries in this study, 16 had a measured NASCET linear percentage angiographic stenosis of $70 \%$ or greater, and 9 had stenoses of less than $70 \%$. In the $70 \%$ or greater group,
Table 1 Results of identifying significant (NASCET > 70\%) stenoses at a Doppler PSV threshold of $296.5 \mathrm{~cm} / \mathrm{s}$ and corresponding rSNI.

\begin{tabular}{llclc|} 
& PSV $^{1}(\mathbf{c m} / \mathbf{s})$ & & \multicolumn{2}{c}{ corresponding SNI } \\
\hline $\begin{array}{l}\text { NASCET } \\
\text { stenosis }\end{array}$ & $<296.5$ & $>296.5$ & $<42.4$ & $>42.4$ \\
$>$ or $=70 \%$ & 7 & 2 & 7 & 2 \\
\hline $70 \%$ & 6 & 10 & 3 & 13 \\
\hline
\end{tabular}

1 PSV: Peak systolic velocity

${ }^{2}$ rSNI: Revised Sonographic NASCET Index

Table 2 Results of identifying significant (NASCET > 70\%) stenoses at a Doppler PSV threshold of $230 \mathrm{~cm} / \mathrm{s}$ and corresponding rSNI.

\begin{tabular}{|llclc|} 
& \multicolumn{2}{l}{ PSV $^{1}$ Threshold } & \multicolumn{2}{c|}{ corresponding rSNI $^{2}$} \\
\hline $\begin{array}{l}\text { NASCET } \\
\text { stenosis }\end{array}$ & $<230$ & $>230$ & $<34.3$ & $>34.3$ \\
\hline$>$ or $=70 \%$ & 7 & 2 & 7 & 2 \\
\hline$<70 \%$ & 6 & 10 & 4 & 12 \\
\hline
\end{tabular}

${ }^{1}$ PSV: Peak systolic velocity

2 rSNI: Revised Sonographic NASCET Index

the PSV threshold of $296.5 \mathrm{~cm} / \mathrm{s}$ correctly identified 10 of 16 stenoses, whereas 13 of 16 were correctly identified by the corresponding rSNI threshold of 42.4. Both PSV and rSNI criteria showed a true-negative rate of 7 out of 9 in the less than $70 \%$ group ( $\bullet$ Table 1 ).

A second comparison between the PSV and rSNI criteria was undertaken at a lower PSV threshold of $230 \mathrm{~cm} / \mathrm{s}$ (see Discussion). The rSNI value that corresponded to this PSV threshold was 34.4. This value was obtained using the PSV versus angiographic stenosis linear regression equation in 0 Fig. 3 to identify the degree of angiographic stenosis corresponding to a PSV of $230 \mathrm{~cm} / \mathrm{s}$ in our data set. This value of angiographic stenosis was then used in the rSNI versus angiographic stenosis linear regression equation ( $\bullet$ Fig. 3) to identify the corresponding rSNI value. The relevant data for this set of threshold values are presented in $\bullet$ Table 2 .

In the $70 \%$ or greater group, 12 of 16 stenoses were correctly identified by the PSV threshold of $230 \mathrm{~cm} / \mathrm{s}$, whereas 15 of 16 were correctly identified by the corresponding rSNI threshold of 34.4. PSV criteria showed a true-negative rate of 6 of 9 , whereas rSNI criteria showed a true-negative rate of 7 of 9 in the less than $70 \%$ group ( Table 2 ).

Comparing the PSV threshold of $296.5 \mathrm{~cm} / \mathrm{s}$ to the corresponding rSNI value of 42.4 for angiographic stenosis of $70 \%$ or greater, the sensitivity, specificity, and overall accuracy of Doppler sonography were $63 \%$ vs. $81 \%, 78 \%$ vs. $78 \%$, and $68 \%$ vs. $80 \%$, respectively. Comparing a PSV threshold of $230 \mathrm{~cm} / \mathrm{s}$ and the corresponding rSNI value of 34.3 for angiographic stenoses of $70 \%$ or greater, the sensitivity, specificity, and overall accuracy of Doppler sonography were $75 \%$ vs. $94 \%, 67 \%$ vs. $78 \%$, and $72 \%$ vs. $88 \%$, respectively. Thus, the rSNI showed higher sensitivity, specificity, and accuracy when compared with those of PSV at both measured thresholds. The rSNI also shows a signifcantly higher correlation coefficient with measured angiographic stenosis than the ICA/ CCA ratio ( $\bullet$ Fig. 4$)$.

However, the original SNI maintained a minimally better correlation with the measured NASCET linear percentage angiographic stenosis $\left(r^{2}=0.55\right)$ as compared to the rSNI $\left(r^{2}=0.47\right)$ ( $\bullet$ Fig. 5 ). Again using the value of PSV corresponding to a NASCET linear 


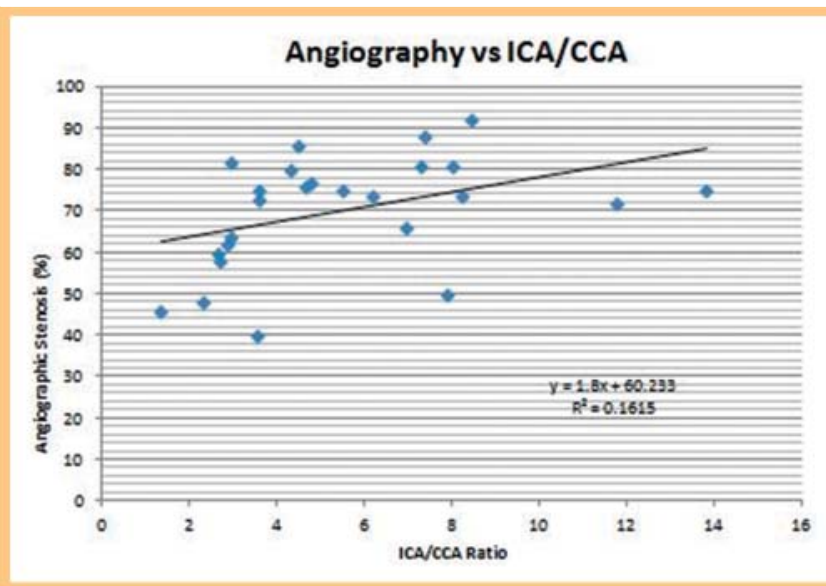

Fig. 4 Linear regression analysis of measured carotid artery angiographic stenosis against the ratio of the peak systolic velocities for the internal carotid artery and common carotid artery (ICA/CCA).

Abb. 4 Lineare Regressionsanalyse der angiografisch gemessenen A. carotis Stenose im Vergleich zur Ratio der systolischen Maximalgeschwindigkeit (PSV) von A. carotis interna und A. carotis communis (ICA/CCA).

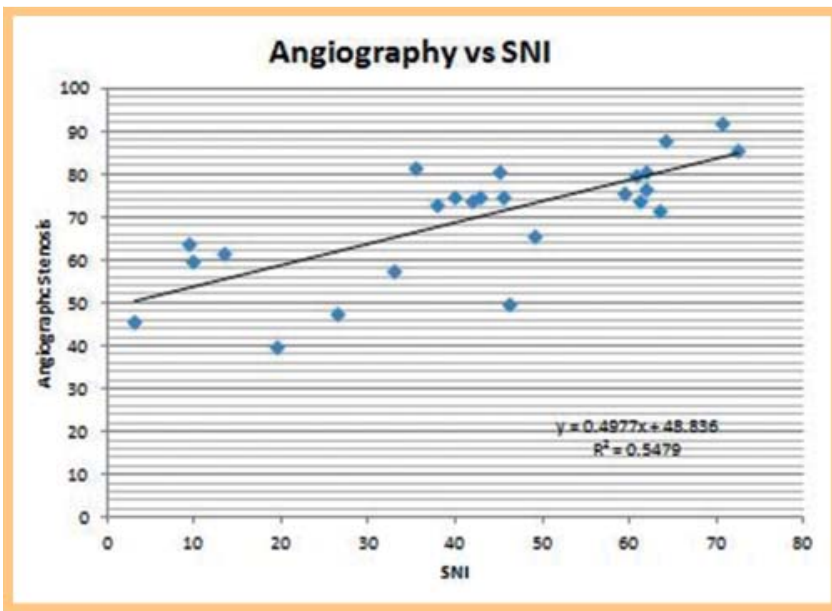

Fig. 5 Linear regression analysis of measured carotid artery angiographic stenosis against the calculated original SNI metric.

Abb. 5 Lineare Regressionsanalyse der angiografisch gemessenen A. carotis Stenose im Vergleich zum errechneten originalen SNI.

percentage angiographic stenosis of $70 \%$ of $296.5 \mathrm{~cm} / \mathrm{s}$, the original SNI value that corresponded to a NASCET linear percentage angiographic stenosis of $70 \%$ was determined to be 42.5 .12 of the 16 stenoses measuring $70 \%$ or greater were identified by the original SNI value (as compared to $13 / 16$ by the rSNI) as shown in - Table 3, giving a slightly lower accuracy rate of $76 \%$ (compared to $80 \%$ with the rSNI). Comparing the PSV threshold of $296.5 \mathrm{~cm} /$ $\mathrm{s}$ to the corresponding revised SNI value of 35.4 for angiographic stenosis of $70 \%$ or greater, the sensitivity and specificity of Doppler sonography were $63 \%$ vs. $75 \%, 78 \%$ vs. $78 \%$, respectively. The sensitivity, specificity, and overall accuracy of the original SNI at the second PSV threshold of $230 \mathrm{~cm} / \mathrm{s}$ were identical to that of the aforementioned rSNI.
Table 3 Results of identifying significant (NASCET > $70 \%$ ) stenoses at a Doppler PSV threshold of $296.5 \mathrm{~cm} / \mathrm{s}$ and corresponding original SNI.

\begin{tabular}{llllc|} 
& \multicolumn{2}{c}{ PSV $^{1}(\mathbf{c m} / \mathbf{s})$} & & \multicolumn{2}{c|}{ corresponding SNI } \\
\hline $\begin{array}{l}\text { NASCET } \\
\text { stenosis }\end{array}$ & $<296.5$ & $>296.5$ & $<42.5$ & $>42.5$ \\
$>$ or $=70 \%$ & 7 & 2 & 7 & 2 \\
\hline$>70 \%$ & 6 & 10 & 4 & 12 \\
\hline
\end{tabular}

1 PSV: Peak systolic velocity

2 SNI: Original Sonographic NASCET Index

\section{Discussion}

$\nabla$

The Society of Radiologists in Ultrasound (SRU) consensus statement published in 2003 stated that Doppler sonography is often the sole imaging technique used before surgery for the evaluation of carotid stenosis [22]. In fact, the SRU panelists estimated that as many as $80 \%$ of patients in the United States undergo carotid endarterectomy with sonographic examination as the only preoperative imaging study. However, given that the benefit of carotid endarterectomy in high-grade stenoses $(>70 \%)$ has been proven to be much more significant than in moderate stenoses (50$69 \%$ ) [23], there is significant controversy about the ability of carotid ultrasound to accurately stratify the degree of carotid stenosis [18]. In fact, a recent American Heart Association statement suggested that carotid ultrasound be used as a screening tool, but not as the sole imaging test in surgical decision-making [24]. This is, in part, because there is no single hemodynamic criterion which has been universally shown to stratify carotid stenosis with sufficient accuracy vis-à-vis the NASCET methodology [18]. For example, PSV, the most commonly used hemodynamic criterion, shows significant scatter when plotted against angiographic stenosis, preventing reliable estimation of the degree of stenosis, regardless of the PSV cut-off used [18]. There is also controversy surrounding the role of B-mode ultrasound to directly estimate stenosis measuring proximal and distal ICA diameters [25].

The prior study by Hathout et al. suggested that the mathematic incorporation of NASCET principles of measurement may help further delineate such stenosis, and created the SNI derivation to specifically mirror the NASCET measurement of angiographic stenosis using the assumption of mass balance. In this paper, a revised SNI (the rSNI) is presented, and compared with both PSV and the SNI. As before, two sets of threshold values were prospectively chosen to compare rSNI to the PSV, the first derived from the regression analysis of PSV versus measured angiographic stenosis corresponding to a stenosis of $70 \%$, and the second threshold at $230 \mathrm{~cm} / \mathrm{s}$, which is the threshold value for high-grade stenosis currently used in our vascular laboratory, as proposed by Berland and Weber [26] for diagnosing 70 - 99\% stenosis.

At the time of the first publication, it was noted that a limitation of the SNI measurement was its reliance on velocity measurements at a single time point (the point of PSV). The derivation was intentionally kept simple in order for the original SNI to be easily computed in the vascular laboratory.

However, it was felt that full characterization of the complex flow dynamics that occur within significant stenosis could not be represented by a single PSV measurement alone. Physiologically, as a vessel narrows, the blood flow velocity must increase to maintain flux (the essence of our mass-balance argument). The true mass-balance equation dictates that bulk flow in must equal bulk flow out, and we have assumed the true bulk volume of 
blood in these diseased vessels should be equal at the proximal and distal sites, as measured by an integral of the area under the recorded waveform. Even the current study does not truly represent bulk flow, as that would require insonating across the entire vessel, and not just taking a waveform from the vessel center, which may have a different flow profile than closer to the vessel walls. However, it was felt that the rSNI, as presented, at least goes some of the way toward characterizing the hemodynamic changes of stenosis using the entire waveform, rather than a single velocity point or a mean velocity. This is because the area under the curve could differ depending on the shape of the velocity envelope, even for identical PSV or mean velocity measurements between two waveforms. Thus, a main aim of this study was to check whether the rSNI would show significantly greater accuracy in detecting significant carotid stenosis (and excluding non-hemodynamically significant stenosis) as compared with the original SNI. In other words, is the significant increase in labor required to calculate the rSNI necessary and justified by significantly higher accuracy rates? As with the original SNI, the rSNI demonstrated increased sensitivity, specificity, and accuracy when compared to the PSV in detecting stenosis of $70 \%$ or greater. However, the overall correlation with angiographic stenosis was not superior to that of the original SNI, and the accuracy only slightly better. Thus, the original method of calculating SNI should suffice in detecting high-grade stenosis, with the obvious advantage of negating the need for additional, time-consuming software analysis in the vascular laboratory to integrate the Doppler waveform and compute the rSNI.

Possible reasons why there is only a minimal difference in accuracy between the SNI and the rSNI may have to do with the specific limitations of this study as well as the general limitations involved in trying to correlate hemodynamic parameters on ultrasound to NASCET style measurements of angiographic stenosis. One potential limitation of this study is that the derivation of the rSNI equation assumes a concentric stenosis with a circular residual lumen (see Methods). However, carotid stenoses are often not concentric, but rather eccentric, semicircular, or irregular. However, this limitation could conceivably be turned into an advantage as well, since the derivation begins by assuming mass balance and relating the bulk flow integrals in the stenosis and in the normal distal ICA to vessel cross-sectional areas. Hence, the derivation could emphasize this relationship as:

$\frac{\text { Area }_{\mathrm{p}}}{\text { Area }_{\mathrm{d}}}=\frac{\int \mathrm{V}_{\mathrm{d}}(\mathrm{t}) \mathrm{dt}}{\int \mathrm{V}_{\mathrm{p}}(\mathrm{t}) \mathrm{dt}}$

It is noted that angiography measures luminal diameter, but the hemodynamic effect of the stenosis is due to luminal area reduction [27]. Hence, although this modified index relating cross-sectional areas is not directly correlated to NASCET diameter measurements, particularly with irregular stenoses, it may actually be a clinically more relevant hemodynamic measure.

A second limitation of the rSNI is the reliance on the spectral envelope, and its conversion to a velocity-time curve, which is then integrated. The spectral envelope is dominated by the highest frequencies, which, in turn, may correspond to streamlines from the outlet of the stenosis which are not parallel to the vessel axis [27]. However, the frequency-velocity conversion would assume an angle of insonation parallel to the vessel lumen, leading to potential overestimation of velocities [27]. Moreover, accurate angle estimation itself is difficult, since the dominant flow stream may not be parallel to the vessel axis. Even with color flow, turbulence and disturbed or helical flow patterns may produce incorrect es- timates of the Doppler angle [27]. Further limitations in spectral analysis are introduced because of spectral broadening. All of these issues introduce non-systematic errors, likely of different magnitudes depending on the patient and the sonologist, and limit the degree of correlation between any hemodynamic index and the degree of stenosis. This is further complicated by the fact that hemodynamic changes, such as an increase in PSV, depend not only on the degree of stenosis, but on additional factors, such as the resultant pressure drop across the stenosis, which is in turn influenced by such things as collateral flow [27]. This was a main consideration in deciding to use the entire waveform in the analysis of the rSNI, as compared to the original SNI index, which used only the peak systolic velocity. It was of interest to investigate whether using the entire waveform, with the concomitant changes in the flow envelope and diastolic flow resulting from these variable hemodynamic factors, would yield a more accurate index vis-à-vis NASCET-style angiographic stenosis.

It should be again noted that at our institution, decisions regarding intervention continue to be based on both MR angiography and sonography and the relative concordance of their findings, as the combination of imaging modalities remains superior to either technique alone [28].

However, it may be possible to move from multi-modality concordance to multiparameter estimation using ultrasound alone, and achieve similar accuracy to a multimodality approach, at least for clearly high-grade or low-grade stenosis. This approach has been well reviewed by von Reutern et al., and includes incorporating such criteria as the presence of collateral flow, average PSV, post-stenotic PSV, and end-diastolic velocities, in addition to the standard PSV in the stenosis [18]. The rSNI, in some sense, incorporates multiple parameters simultaneously, since the shape of the waveform reflects PSV, end-diastolic velocity and average velocity. Also, the assessment is carried out both with the stenosis and in the post-stenotic segment of the ICA. This multiparametric nature may explain why the rSNI is more accurate than PSV alone. Moreover, the rSNI itself can be incorporated as an additional parameter in a multiparametric approach. In our series, when using a combined threshold of PSV $=296 \mathrm{~cm} / \mathrm{sec}$ and $\mathrm{rSNI}=42$, the positive predictive value of a high-grade angiographic stenosis was $91 \%$, which is higher than either PSV or the rSNI alone ( $83 \%$ and $87 \%$ respectively). Using the low end of the ranges, with a combined threshold of $P S V=230 \mathrm{~cm} / \mathrm{sec}$ and $\mathrm{rSNI}=34$, there is a negative predictive value of $83 \%$ for excluding significant stenosis, again significantly better than PSV alone (60\%), but slightly worse than rSNI alone (87.5\%).

\section{Conclusion}

\section{$\nabla$}

The rSNI, mirroring the NASCET methodology of stenosis, shows greater sensitivity, specificity and overall accuracy in detecting significant ICA stenosis as compared with the conventional Doppler parameter of PSV. Although the originally proposed SNI, which specifically mirrors the NASCET methodology of stenosis measurement, uses a single velocity time point and does not incorporate the full Doppler waveform, it is comparable to the rSNI, being only slightly less accurate but actually having a slightly better correlation coefficient with linear regression analysis. A larger, prospective study is needed for further confirmation of these conclusions, but we recommend use of the SNI instead of conventional Doppler parameters in the assessment of carotid stenosis, and suggest that while the rSNI is more theoretically robust, the 
simpler SNI should be fully adequate for easy use in the ultrasound laboratory. Furthermore, we suggest that the SNI or the rSNI be incorporated into the emerging multiparametric approaches in using ultrasound in the evaluation of carotid stenosis.

\section{References}

1 Jacobs NM, Grant EG, Schellinger $D$ et al. Duplex carotid sonography: criteria for stenosis, accuracy, and pitfalls. Radiology 1985: 385

2 Moneta GL, Edwards JM, Chitwood RW et al. Correlation of North American Symptomatic Carotid Endarterectomy Trial (NASCET) angiographic definition of $70 \%$ to $99 \%$ internal carotid artery stenosis with duplex scanning. J Vasc Surg 1993; 17: 152

3 Neale ML, Chambers JL, Kelly AT et al. Reappraisal of duplex criteria to assess significant carotid stenosis with special reference to reports from the North American Symptomatic Carotid Endarterectomy Trial and the European Carotid Surgery Trial. J Vasc Surg 1994; 20: 642

4 Moneta GL, Edwards JM, Papanicolaou G et al. Screening for asymptomatic internal carotid artery stenosis: duplex criteria for discriminating 60\% to 99\% stenosis. J Vasc Surg 1995; 21: 989

5 Hood DB, Mattos MA, Mansour A et al. Prospective evaluation of new duplex criteria to identify $70 \%$ internal carotid artery stenosis. J Vasc Surg 1996; 23: 254

6 Huston J III, James EM, Brown RD Jr et al. Redefined duplex ultrasonographic criteria for diagnosis of carotid artery stenosis. Mayo Clin Proc 2000; 75: 1133

7 Friese $S$, Krapf $H$, Fetter $M$ et al. Ultrasonography and contrast-enhanced MRA in ICA-stenosis: is conventional angiography obsolete? J Neurol 2001; 248: 506

8 Filis KA, Arko FR, Johnson BL et al. Duplex ultrasound criteria for defining the severity of carotid stenosis. Ann Vasc Surg 2002; 16: 413

9 Patel SG, Collie DA, Wardlaw JM et al. Outcome, observer reliability, and patient preferences if CTA, MRA, or Doppler ultrasound were used, individually or together, instead of digital subtraction angiography before carotid endarterectomy. J Neurol Neurosurg Psychiatry 2002; 73: 21

10 Staikov IN, Nedeltchev K, Arnold M et al. Duplex sonographic criteria for measuring carotid stenosis. J Clin Ultrasound 2002; 30: 275

11 Borisch I, Horn M, Butz B et al. Preoperative evaluation of carotid artery stenosis: comparison of contrast-enhanced MR angiography and duplex sonography with digital subtraction angiography. AJNR Am J Neuroradiol 2003; 24: 1117

12 Wiley S. Choosing modalities for carotid stenosis. J AHIMA 2003; 74: 90
13 Rao VM, Parker L, Smith RL et al. Relative roles of imaging modalities in carotid disease: an analysis of a fee-for service health insurance database [abstract]. Radiology 2000; 217: 260

14 Tholen AT, de Monyé C, Genders TS et al. Suspected carotid artery stenosis: cost-effectiveness of CT angiography in work-up of patients with recent TIA or minor ischemic stroke. Radiology 2010; 256: 585

15 Sabeti S, Schillinger M, Mlekusch W et al. Quantification of internal carotid artery stenosis with duplex US: comparative analysis of different flow velocity criteria. Radiology 2004; 232: 431

16 Grant EG, Duerinckx AJ, El Saden SM et al. Ability to use duplex US to quantify internal carotid arterial stenoses: fact or fiction? Radiology 2000; 214: 247

17 Lee VS, Hertzberg BS, Workman MJ et al. Variability of Doppler US measurements along the common carotid artery: effects on estimates of internal carotid arterial stenosis in patients with angiographically proved disease. Radiology 2000; 214: 387

18 von Reutern GM, Goertler MW, Bornstein NM et al. Grading carotid stenosis using ultrasonic methods. Stroke 2012; 43: 916-921

19 Fox AJ. How to measure carotid stenosis. Radiology 1993; 186: 316

20 Hathout GM, Fink JR, El-Saden SM et al. Sonographic NASCET index: a new doppler parameter for assessment of internal carotid artery stenosis. AJNR Am J Neuroradiol 2005; 26: 68

21 North American Symptomatic Carotid Endarterectomy Trial Collaborators. Beneficial effect of carotid endarterectomy in symptomatic patients with high-grade carotid stenosis. N Engl J Med 1991; 325: 445

22 Grant EG, Benson CB, Moneta GL et al. Carotid artery stenosis: grayscale and Doppler US diagnosis-Society of Radiologists in Ultrasound Consensus Conference. Radiology 2003; 229: 340

23 Rothwell PM, Eliasziw M, Gutnikov SA et al. Analysis of pooled data from the randomized controlled trials of endarterectomy for symptomatic carotid stenosis. Lancet 2003; 361: 107

24 Latchaw RE, Alberts MJ, lev MH et al. Recommendations for imaging of acute ischemic stroke: a scientific statement from the American Heart Association. Stroke 2009; 40: 3646-3678

25 Lee KW, Park YJ, Rho YM et al. Measurement of carotid stenosis: correlation analysis between B-mode ultrasonography and contrast arteriography. J Korean Surg Soc 2011; 80: 348-354

26 Berland L, Weber T. Carotid. In: McGahan JP, Goldberg BB eds. Diagnostic Ultrasound: A Logical Approach. 1998. Philadelphia, PA: LippincottRaven; 1022

27 von Reutern GM. Measuring the degree of internal carotid artery stenosis. Perspectives in Medicine 2012; 1: 104-107

28 Johnston DC, Goldstein LB. Clinical carotid endarterectomy decisionmaking: noninvasive vascular imaging versus angiography. Neurology 2001; 56: 1009 